\title{
LITERASI DIGITAL BAGI SISWA, GURU, DAN KARYAWAN DI LINGKUNGAN SMP MUHAMMADIYAH NANGGULAN KULON PROGO
}

\author{
Ani Yuliati'1), Laga Adhi Dharma1), Nur Alifah Septiani'1), Adnin Kamil B. Hawa1), \\ Malinda Satya Ningrum ${ }^{1)}$
}

\author{
${ }^{1)}$ Sastra Indonesia, Fakultas Sastra, Budaya, dan Komunikasi, Universitas Ahmad Dahlan, Yogyakarta, Daerah Istimewa \\ Yogyakarta, Indonesia \\ Corresponding author : Nur Alifah Septiani \\ E-mail : nur.alifah@idlitera.uad.ac.id
}

Diterima 27 November 2021, Disetujui 03 Desember 2021

\begin{abstract}
ABSTRAK
Di era pandemi seperti sekarang ini semua bidang kehidupan mengalami perubahan atau pergeseran, tidak terkecuali juga bidang pendidikan. Hal ini dirasakan juga oleh sekolah menengah pertama (SMP) Muhammadiyah Nanggulan, Kulon Progo. Berbagai permasalahan yang ada di sekolah itu di antaranya minimnya sarana dan prasarana berkaitan dengan literasi digital dan rendahnya minat baca siswa. Berkaitan dengan dua hal tersebut, diadakanlah kegiatan pengabdian kepada masyarakat berupa penyuluhan program literasi digital bagi guru, siswa, dan karyawan SMP Muhammadiyah Nanggulan serta pembentukan semacam forum/komunitas siswa sebagai untuk meningkatkan kemampuan literasinya. Peningkatan literasi baca tulis siswa, guru, dan karyawan di SMP Muhammadiyah Nanggulan dilakukan pelatihan dan pendampingan serta pembentukan pojok baca dan pembentukan majalah sekolah "Sumunar" sebagai wadah bagi siswa, guru, dan karyawan untuk mengasah kemampuan literasinya.
\end{abstract}

Kata kunci: literasi digital; SMP muhammadiyah nanggulan; kulon progo

\begin{abstract}
In the current pandemic era, all areas of life experience changes or shifts, including the field of education. This is also felt by the Muhammadiyah Nanggulan junior high school, Kulon Progo. Various problems that exist in the school include the lack of facilities and infrastructure related to digital literacy and the low interest in reading students. In connection with these two things, community service activities were held in the form of digital literacy program counseling for teachers, students, and employees of Muhammadiyah Nanggulan Junior High School and the establishment of a kind of forum/student community to improve their literacy skills. To improve the literacy of students, teachers, and employees at SMP Muhammadiyah Nanggulan, training and mentoring are carried out as well as the establishment of a reading corner and the establishment of the school magazine "Sumunar" as a forum for students, teachers, and employees to hone their literacy skills.
\end{abstract}

Keywords: digital literacy; muhammadiyah nanggulan junior high school; kulon progo

\section{PENDAHULUAN}

SMP Muhammadiyah Nanggulan merupakan sekolah yang terletak di sebuah perbukitan di daerah Kulon Progo. Sarana dan Prasarana sekolah tersebut cukup minim. Koleksi perpustakaan yang sangat terbatas merendahkan tingkat literasi siswa SMP Muhammadiyah Nanggulan. Kondisi pandemi Covid-19 yang hampir melumpuhkan aktivitas masyarakat sehingga siswa-siswa pun harus melakukan pembelajaran secara daring. Pembelajaran daring memangkas ruang dan waktu sehingga memudahkan dalam transfer informasi. Akan tetapi dalam pembelajaran daring yang tanpa diimbangi dengan pengetahuan yang cukup akan memiliki dampak negatif. Hal itu seperti yang dikemukakan oleh Khurriyati et al (2021) yang menemukan adanya dampak negatif dari pembelajaran daring yakni ketidakpedulian siswa terhadap kewajibannya sebagai siswa dan ketergantungan siswa terhadap orang lain. Selain itu dalam pembelajaran daring siswa akan lebih lekat dengan gawai. Kondisi ini juga akan mempengaruhi kondisi siswa. Gawai mampu menawarkan beraneka ragam informasi dari berbagai penjuru dunia. Hal ini apabila tidak dikelola dengan baik akan menimbulkan dampak negatif bagi generasi muda Indonesia. Pratiwi dan Pritanova dalam 
Silvana \& Cecep (2018) mengatakan terkait pemahaman digital yang kurang baik memilki pengaruh pada perkembangan psikologis anak dan remaja. Oleh karena itu penyuluhan terkait literasi digital menjadi penting dilakukan bagi generasi muda Indonesia.

Berdasarkan wawancara dengan Kepala Sekolah SMP Muhammadiyah Nanggulan, diperoleh barbagai masalah yang dapat diangkat sebagai tema pengabdian masyarakat yaitu (1) rendahnya minat baca para siswa, (2) belum ada program literasi digital yang dilakukan oleh pihak luar, (3) jumlah koleksi buku di perpustakaan masih kurang, (4) minat siswa berkunjung ke perpustakaan masih rendah, dan (5) pengelolaan perpustakaan terkendala SDM. Oleh karena itu Tim PPM dari Program Studi Sastra Indonesia, Universitas Ahmad Dahlan menekankan pada program literasi digital untuk meningkatkan kemampuan literasi semua eleman yang ada di sekolah yaitu siswa, guru, dan karyawan. Hal ini senada dengan pernyataan Dirjen Aplikasi Informatika Semuel A. Pangerapan yang mengajak semua pihak ikut serta meningkatkan literasi digital masyarakat(Agustini, 2021).

Kegiatan ini diupayakan berkelanjutan karena kondisi sekolah yang berada di daerah pinggiran dan memerlukan uluran tangan berbagai pihak. Kegiatan ini merupakan upaya mendukung program pemerintah tentang pemerataan pendidikan dengan pengembangan perpustakaan dan literasi digital. Hal ini mengacu pada Peraturan Presiden Bab 27 tentang peningkatan akses masyarakat terhadap pendidikan yang berkualitas(Peraturan Presiden Bab 27, n.d.).

Dengan kegiatan PPM ini diharapkan para siswa di SMP Muhammadiyah Nanggulan dapat merutinkan kegiatan literasi bersama guru dan karyawan di sekolah sehingga ke depannya siswa-siswa dapat membuat karya seperti puisi, cerpen, dan karya ilmiah yang dapat diikutsertakan dalam berbagai kompetisi. Pelatihan sitasi dalam penulisan karya ilmiah merupakan hal yang sangat dibutuhkan di era digital. Kerentanan terhadap tulisan yang mudah diplagiasi atau melakukan palgiasi di era digital menjadi momok tersendiri. Menurut Shadiqi dalam Sari \& Adam (2021) pada era digital yang paperless perilaku palgiarisme dapat mudah tumbuh karena kemudahan dalam melakukan copy paste atau penyalinan tulisan melalui internet.

Selain itu, perpustakaan yang ada dapat dikembangkan dan dikelola dengan cara yang baik, sehingga dapat dimanfaatkan secara maksimal. Kegiatan ini juga diharapkan dapat meningkatkan prestasi di lingkungan SMP Muhammadiyah Nanggulan. Praktik pendidikan di era literasi digital memerlukan inovasi dan kreasi yang terus-menerus sehingga guru maupun anak didik tidak mudah mengalami kejenuhan dan kebosanan (Sumiati \& Wijanarko, 2020).

\section{METODE}

Metode yang dilakukan dalam kegiatan PPM ini berupa penyuluhan dan pendampingan. Penyuluhan berkaitan dengan pentingnya literasi digital dan upaya pembenahan perpustakaan sekolah agar literasi digital dapat ditingkatkan. Adapun pendampingan berupa perintisan pojok baca secara daring untuk media informasi dan pembelajaran siswa. Tim PPM memilki tiga kepakaran yakni linguistik, sastra modern, sastra dan budaya. Tim pakar linguistik memberikan penyuluhan pentingnya literasi digital di era pandemi, bersama tim membentuk forum pojok baca dan melakukan pendampingan kepada para siswa dan guru untuk menulis. Adapun tim sastra (sastra modern maupun sastra dan budaya). Nur Alifah Septiani (Sastra Modern) memberikan penyuluhan pentingnya wahana untuk melatih kreativitas anak-anak dalam kegiatan menulis (karya fiktif dan tulisan ilmiah), bersama tim membentuk forum pojok baca dan melakukan pendampingan kepada para siswa untuk menulis. Selain itu juga memberikan penyuluhan dan pendampingan pengelolaan perpustakaan berbasis digital. Kegiatankegiatan yang dilaksanakan dibagi menjadi dua skema, daring dan luring. Kegiatan ini dimulai dari bulan Juni sampai dengan November 2021. Jumlah peserta yang mengikuti kegiatan ini kurang lebih terdapat 12 siswa perwakilan siswa dari kelas 7,8 dan 9 SMP Muhammadiyah Nanggulan. Selain itu, terdapat juga guru SMP Muhammadiyah Nanggulan yang terlibat dalam pendampingan Tim PPM, khususnya guru-guru yang akan mengikuti lomba karya tulis ilmiah. Guru-guru didampingi dalam menajamkan ide dan analisis pada karya tulis ilmiah yang dibuat.

\section{HASIL DAN PEMBAHASAN \\ Persiapan Digitalisasi Koleksi Perpustakaan} Digitalisasi koleksi perpustakaan dimulai tanggal 10 Juli 2021. Kegiatan yang sudah dilakukan adalah menyiapkan file yang berisi koleksi buku-buku yang diperlukan sekolah seperti novel, antologi cerpen, antologi puisi, dan buku-buku cerita yang mengandung unsur pendidikan. Berikut ini sebagian koleksi yang dikumpulkan untuk menambah referensi yang ada di perpustakaan sekolah SMP Muhammadiyah Nanggulan. 


\section{Pembentukan Forum Pojok Baca}

Untuk meningkatkan kemampuan literasi di lingkungan SMP Muhammadiyah Nanggulan dibentuklah "Pojok Baca". "Pojok Baca" adalah sebuah arena di sudut perpustakaan SMP Muhammadiyah Nanggulan. Tempat ini dapat digunakan untuk membaca referensi, berdiskusi, maupun berkarya bagi siswa maupun guru di SMP Muhammadiyah Nanggulan. Selanjutnya, forum Pojok Baca dikembangkan sebagai sebuah komunitas yang didukung pihak sekolah maupun mitra yaitu tim dosen dan mahasiswa UAD. Dengan adanya komunitas ini diharapkan muncul ide-ide kreatif yang dapat menghasilkan karya, baik dari siswa, guru, maupun karyawannya.

\section{Pendampingan kepada para siswa untuk menulis karya \\ Adanya Komunitas Pojok Baca} memotivasi anak untuk menulis dan berkarya. Di sini ditekankan pentingnya kegiatan menulis dalam bidang pendidikab maupun kehidupan sehari-hari. Pendampingan menulis bagi siswa SMP Muhammadiyan Nanggulan dilakukan secara daring melalui grup WA Sampai saat ini sudah terkumpul beberapa tulisan dan lukisan siswa yang akan diterbitkan dalam majalah "Sumunar" edisi perdana.

\section{Kunjungan ke sekolah}

Setelah melakukan kegiatan penyuluhan dan pendampingan secara daring, tim PPM Prodi Sastra Indonesia berkunjung ke SMP Muhammadiyah Nanggulan. Adapun kegiatan yang dilakukan adalah

a. penyerahan poster kegiatan PPM

b. penyerahan sumbangan referensi Pojok Baca

c. penyerahan kelengkapan sarana sekolah (taplak meja)

d. penyerahan rencana desain halaman sampul majalah "SUMUNAR"

\section{Hasil yang dilakukan kepada mitra}

Kondisi SMP Muhammadiyah

Nanggulan, Kulon Progo sebagai sekolah swasta di daerah pinggiran Yogyakarta perlu mendapat perhatian. Sarana prasarana yang ada juga masih terbatas, terutama berkaitan dengan koleksi buku di perpustakaan. Di sisi lain jumlah SDM juga belum memadai. Masalah lain adalah jumlah siswa yang sedikit dan belum pernah mengikuti berbagai lomba/kejuaraan baik tingkat lokal maupun nasional.

Dengan latar belakang di atas, tim PPM dari Prodi Sastra Indonesia memberikan pelatihan berkaitan dengan kegiatan literasi dan memberikan sumbangan berupa koleksi perpustakaan yang berupa soft file dan hardfile (buku) serta kelengkapan prasarana sekolah. Kegiatan literasi dibagi menjadi dua yaitu ceramah dan pendampingan. Ceramah telah dilaksanakan secara daring via zoom dengan materi pertama "Digitalisasi Koleksi Perpustakaan dan Wacana Pojok Baca". Materi perdana ini disampaikan oleh Laga Adhi Dharma. Ceramah/pelatihan yang kedua dibawakan oleh Nur Alifah Septiani dengan membawakan topik "Menulis dengan Gembira Bersama Prodi Sastra Indonesia". Adapun materi pelatihan terakhir diberikan oleh Ani Yuliati dengan judul "Pelatihan Literasi Digital bagi Siswa, Karyawan, dan Guru di Lingkungan SMP Muhaammadiyah Nanggulan, Kulon Progo".

Dalam ceramah dan pelatihan tersebut para siswa dan guru didorong untuk selalu meningkatkan kegiatan literasi baik di sekolah, keluarga, maupun masyarakat. Tim kemudian membentuk forum "Pojok Baca" di area perpustakaan sekolah untuk menggiatkan literasi anak, guru, maupun karyawan di SMP Muhammadiyah Nanggulan. Setelah mereka terbiasa dengan kegiatan membaca diharapkan mereka dapat mengembangkan kreativitas menulis. Dalam pelatihan tersebut tim PPM juga mncoba memotivasi siswa untuk berkarya dengan adanya kuis berhadiah. Setelah itu, tim PPM, pihak sekolah (Kepala Sekolah dan guru pendamping) membuat grup "Literasi SMP Muhammadiyah Nanggulan" untuk pendampingan karya anak-anak maupun guru. Akhirnya terkumpul karya para siswa berupa puisi, cerita lucu,dan gambar/lukisan. Dengan kolaborasi guru, siswa, dan tim PPM Prodi Sastra Indonesia , SMP Muhammadiyah Nanggulan telah memiliki media literasi berupa majalah yang diberi nama SUMUNAR.

Berdasarkan interksi selama penyuluhan, terlihat bahwa sebenarnya anakanak dapat berkarya dalam bentuk tulisan meskipun masih sederhana. Pendampingan dan motivasi yang kontinyu tentunya sangat diperlukan untuk mengembangkan kemampuan menulis ini mengingat kegiatan menulis sangat penting dalam dunia akademik maupun kehidupan sehari-hari pada umumnya.

Selain siswa, seorang guru di SMP Muhammadiyah Nanggulan juga ikut berpartisipasi dalam lomba nasional berkaitan dengan literasi yang diselenggarakan oleh UT bekerja sama dengan Kemendikbud. Tim PPM melakukan pendampingan selama 1 bulan berkaitan dengan judul artikel, ejaan, kalimat efektif, sitasi, dan unsur plagiarismenya. Meskipun belum mendapatkan kejuaraan, tim tetap mendorong guru maupun siswa untuk tetap berkarya (menulis) karena pentingnya kegiatan tersebut dalam dunia pendidikan maupun dapat menjadi sarana mengembangkan bakat/minat. 
Pelatihan kepenulisan diikuti oleh siswa dan guru SMP Muhammadiyah Nanggulan secara daring. Hal ini terlihat pada gambar di bawah ini, salah satu kegiatan pelatihan penulisan yang dilaksanakan secara daring.

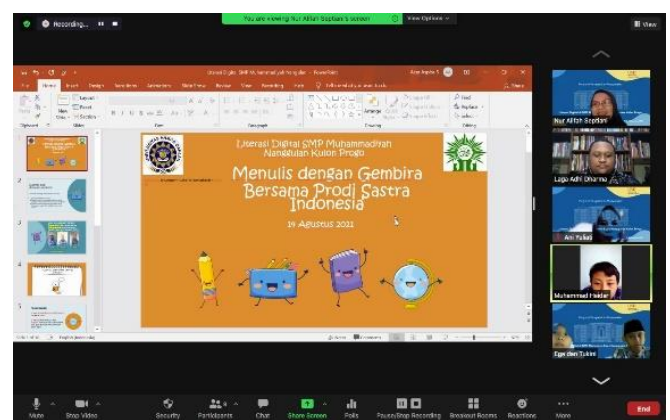

Gambar 1. Pelatihan penulisan secara daring

Pelatihan kepenulisan ini dilakukan untuk membekali siswa dan guru untuk menulis kreatif terutama pada penulisan karya sastra. Hal ini untuk mengasah siswa dan guru dalam mengolah kata dan imajinasi dalam bentuk narasi cerita. Adapun kegiatan lain yang juga menunjang siswa menjadi siswa yang unggul dan melek digital adalah penyuliuhan literasi digital. Program ini diiikutik oleh seluruh siswa, guru, dan karyawan di lingkungan SMP Muhammadiyah Nanggulan. Kegiatan ini dilakukan secara daring karena adanya pemberlakuan pembatasan aktifitas masyarakat karena pandemic Covid-19. Berikut hasil screenshoot kegiatan penyuluhan literasi digital.

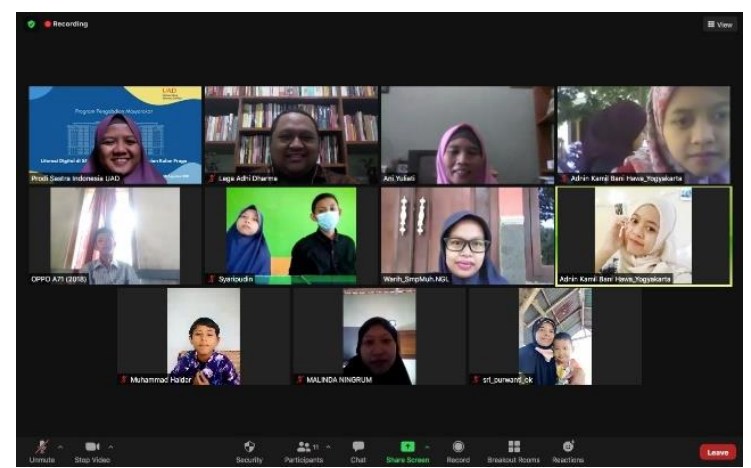

Gambar 2. Penyuluhan literasi digital

Selain kegiatan yang dilakukan secara daring tim PPM juga melakukan kegiatan yakni pembentukan dan sosialisasi pojok baca dan majalah "Sumunar" yang merupakan wadah bagi siswa, guru, dan karyawan SMP Muhammadiyah Nanggulan untuk meningkatkan literasinya. Kegiatan ini dilaksanakan secara luring yang bertempat di SMP Mummadiyah Nanggulan yang dihadiri oleh Tim PPM UAD, Guru, dan para siswa yang jumlahnya sekitar 20 an siswa dengan tetap mengedepankan protokol kesehatan selama kegiatan berlangsung. Adapun kegiatannya dapat dilihat dalam gambar 3 di bawah ini.

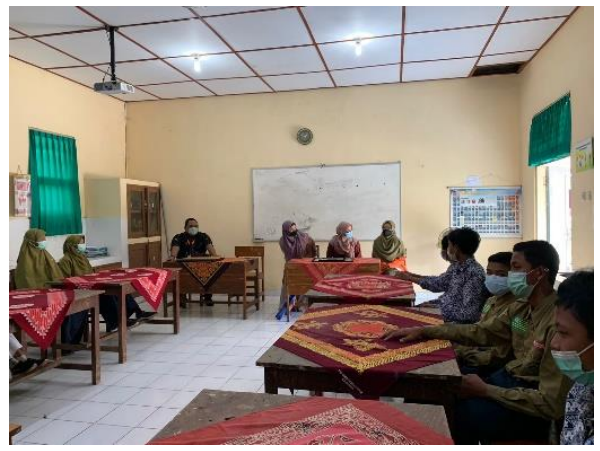

Gambar 3. Sosialiasi pembentukan pojok baca dan majalah "Sumunar"

Dalam kegiatan luring ini, Tim PPM UAD juga mensahkan berdirinya komunitas pojok baca yang ke depannya akan menjadi wadah para siswa agar semakin melek literasi dan harapannya muncul berbagai karya dari komunitas pojok baca tersebut.

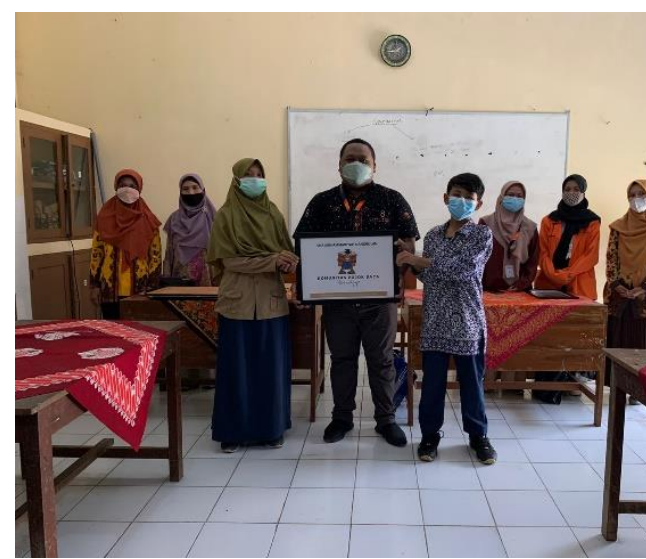

Gambar 4. Penyerahan secara simbolik poster pojok baca

Harapan lain yang bisa disematkan dengan adanya komunitas pojok baca yakni para siswa mampu menulis berbagai macam artiikel yang nantinya dapat diterbitkan di majalah sumunar yang menjadi majalah pertama di SMP Mummadiyah Nanggulan. Majalah ini harapannya berisi berbagai tulisan baik dari siswa maupun guru, tentang berbagai hal baik dari potensi sekolah maupun potensi lingkungan di wilayah nanggulan yang dapat menjadi bahan utama tulisan-tulisan majalah sumunar. Tim PPM UAD juga berharap bahwa majalah ini juga dapat menjadi bacaan yang fresh dan berisi tentang aktivitas yang terdapat di SMP Muhammadiyah Nanggulan dan barangkali para siswa-siswi yang berprestasi di sekolah tersebut dapat dijadikan ulasan di dalam majalah sumunar sehingga dapat memantik dan menjadi inspirasi bagi siswa lainnya. Berikut penyerahan secara simbolik 
majalah sumunar yang diterima langsung oleh kepala SMP Muhammadiyah Nanggulan.

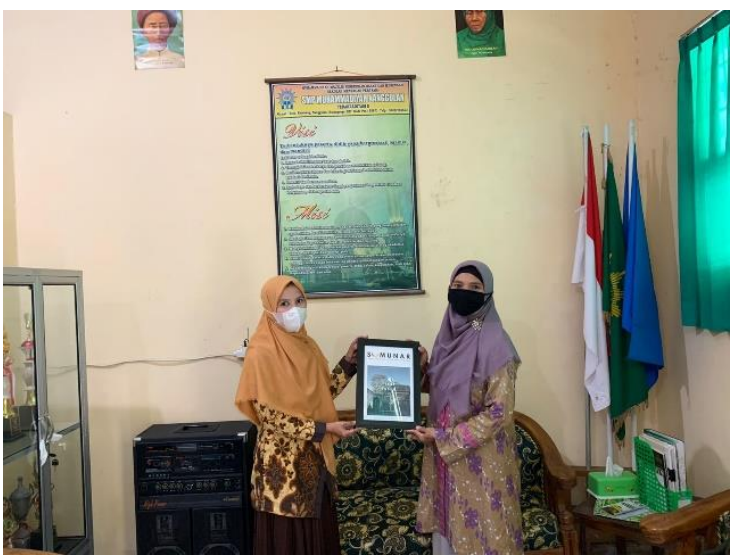

Gambar 5. Penyerahan secara simbolik halam sampul majalah Sumunar

\section{Kontribusi Mitra terhadap pelaksanaan}

Kontribusi mitra terhadap pelaksanaan PPM ini adalah memberikan gambaran kepada tim bahwa di sekolah-sekolah pinggiran begitu banyak siswa dan guru yang perlu mendapat uluran tangan untuk dapat maju dan berprestasi. Hal ini membangun kesadaran bagi dosen maupun mahasiswa untuk ikut membantu masyarakat dengan keilmuan yang dimilikinya dengan kegiatan yang nyata.

\section{Faktor yang menghambat}

Ada beberpa factor yang menghambat kegitaan PPM sebagai berikut:

a. Faktor yang menghambat pelaksanaan PPM ini adalah ketidaksesuaian antara waktu yang dijadwalkan tim dengan kondisi sekolah. Untuk keperluan menyusun luaran antara lain diperlukan dokumentasi berupa video. Waktu yang dijadwalkan tim ternyata bersamaan dengan kegiatan asesmen di sekolah dan pemberlakuan PPKM secara terbatas. Sementara pihak sekolah sudah siap, tim PPM sudah disibukkan dengan berbagai aktivitas di internal prodi.

b. Faktor yang mendukung

c. Faktor yang mendukung kegiatan ini adalah adanya kedekatan secara emosional antara tim PKM dengan pihak mitra. Apalagi komunikasi dengan guru pendamping, kepala sekolah, dan siswa masih terus berlangsung untuk keperluan pendampingan menulis. Tim PPM masih tetap mendampingi siswa dan guru dalam kegiatan yang berkaitan dengan literasi.

d. Solusi dan Tindak Lanjut e. Pelaksanaan kunjungan ke sekolah dilakukan dengan penyerahan poster berkaitan dengan beberapa agenda kegiatan yang telah dilaksanakan sebelumnya. Dengan kata lain, hal ini sudah merangkum semua kegiatan yang dilakukan dalam program yang direncanakan. Hasil dari kegiatan ini tidak dapat langsung dilihat karena kegiatan literasi ini berkaitan dengan pembiasaan dan keterampilan berbahasa.

f. Rencana dan Langkah Strategis Agar Kegiatan dapat Berkelanjutan

g. Agar kegiatan ini dapat berkelanjutan, tim selalu berkomunikasi dengan pihak sekolah terkait pendampingan menulis untuk mengisi rubrik majalah yang telah dibentuk.

\section{SIMPULAN DAN SARAN \\ Simpulan}

Kegiatan pengabdian masyarakat sangat bermanfaat baik bagi pihak mitra maupun tim dosen dan mahasiswa. Dengan kegiatan penyuluhan dan pendampingan menulis di SMP Muhammadiyah Nanggulan, motivasi siswa maupun guru dalam bidang literasi semakin meningkat. Hal ini dibuktikan dengan adanya beberapa karya siswa dan guru yang berupa puisi, cerita lucu, lukisan, maupun artikel ilmiah.

\section{Saran}

Sekolah SMP Muhammadiyah Nanggulan masih kekurangan guru. Kondisi perpustakaan juga tidak terawat dan koleksinya sedikit. Perlu peran mahasiswa untuk dapat membantu menggerakkan komunitas yang ada dan pembenahan perpustakaan sehingga kegiatan PBM dan literasi di sekolah dapat berjalan dengan baik.

\section{UCAPAN TERIMAKASIH}

Terima kasih kepada LPPM Universitas Ahmad Dahlan (UAD) yang telah memberikan dukungan pendanaan dalam pelaksanaan pengabadian masyarakat (PPM) tim Program Studi Sastra Indonesia UAD.

\section{DAFTAR RUJUKAN}

Agustini, P. (2021). Dirjen Aptika: Tingkatkan Literasi Digital di Masa Pandemi. Kementrian Komunikasi Dan Informasi RI Direktorat Jenderal Aplikasi Informatika.

Khurriyati, Y., Setiawan, F., \& Mirnawati, L. B. (2021). Dampak Pembelajaran Daring terhadap Hasil Belajar Siswa MI Muhammadiyah Surabaya. Jurnla IImiah Pendidikan Dasar, VIII(1), 91-104. 
https://doi.org/http://dx.doi.org/10.30659/

pendas.8.1.91-104

Peraturan Presiden Bab 27.

Sari, N. P., \& Adam, L. N. (2021). Upaya Pencegahan Plagiarisme dengan Menggunakan Aplikasi Mendeley dalam Melakukan Penulisan Sitasidan Referensi. Selaparang, 4(3), 586-591. https://doi.org/https://doi.org/10.31764/jp mb.v4i3.4808

Silvana, H., \& Cecep. (2018). Pendidikan Literasi Digital di Kalangan Usia Muda di Kota Bandung. Pedagogia, 16(2), 146156.

https://doi.org/https://doi.org/10.17509/pd gia.v16i2.11327

Sumiati, E., \& Wijanarko. (2020). Manfaat Literasi Digital bagi Masyarakat dan Sektor Pendidikan Pada Saat Pandemi Covid-19. Buletin Perpustakaan Universitas Islam Indonesia, 3(2), 65-80. 